\title{
Structured Word Inquiry (SWI) Teaches Grapheme-Phoneme Correspondences More Explicitly Than Phonics Does: An open letter to Jennifer Buckingham and the reading research community
}

Peter Bowers, February 5, 2021

Contact author < peterbowers1@mac.com>

\section{Dear Dr. Buckingham,}

I am writing this open letter in response to a claim you made about structured word inquiry (SWI) in your article

(Buckingham, 2020), "Systematic phonics instruction belongs in evidence-based reading programs: A response to Bowers" in The Educational and Developmental Psychologist.

First, some background.

My name is Peter Bowers. My brother, Jeff Bowers, wrote the article to which you were responding, "Reconsidering the evidence that systematic phonics is more effective than alternative methods of reading instruction" (J. Bowers, 2020) in Educational Psychology Review. In the interest of full transparency, you should know that the phrase "structured word inquiry" (SWI) was introduced by John Kirby and me in our 2010 intervention study (P. Bowers \& Kirby, 2010); and I am currently self-employed as an educational consultant, training teachers in SWI. The fact that my published research and my self-employment centre on SWI clearly should be factored into anyone's reading of my research and practice.

Equally, I would argue that all research should be read with a critical eye, given that researchers who publish regularly and primarily in support of any particular theory must be especially vigilant against personal bias. It is for that reason we should challenge both new arguments and long-held assumptions with equal vigour.
It won't surprise you that I have a very different take on Jeff's analysis than you. We have addressed those differences in detail elsewhere (J. Bowers \& P. Bowers, 2021). For now, I specifically address the false claim you made -- that SWI does not teach about grapheme-phoneme correspondences and serious consequences that misrepresentation may have for guiding future research. This claim is not just erroneous; it reflects a fundamental misunderstanding of the theory and practice of SWI. The following quote about SWI is from your article:

Official unit outlines or teaching manuals for SWI are not publicly available, so information about instructional methods is anecdotal. Students are encouraged to 'spell words out' using letter names rather than sound them out using GPCs. This contradicts any claim that SWI teaches GPCs, given that GPCs by definition involve the speech sounds associated with the letters, not their names.

(Buckingham, 2020, p. 2).

In direct contrast to your assertion, explicit instruction of grapheme-phoneme correspondences is, and has always been, an essential feature of SWI. The implication of your statement is that spelling words by announcing their letter names precludes any other instruction in grapheme-phoneme correspondence. Your mischaracterization of SWI regarding how it addresses phonology is not new. I regularly see claims in social media and other informal contexts that SWI underemphasizes the importance of grapheme-phoneme correspondences. These are often second-hand claims.

Your stronger, categorical (but false) assertion that SWI doesn't teach grapheme-phoneme correspondences at all is less 
common, but not unique. As far as I know, this is the first assertion of this strong claim in a peer-reviewed journal.

Those who already have heard misinformation about SWI or who have their first encounter with it in your article now have a quote from a well-known researcher in a peer-reviewed journal to support and spread this false argument to others. With that in mind, I felt obliged to clarify this error not only with you but also for the wider public with this open letter.

Before I get into these more crucial issues, I want to highlight a straightforward logical fallacy in your assertion. Even if your characterization of how children are asked to "spell words out" in SWI were accurate (it is not), this would still not justify your statement that this practice "contradicts any claim that SWI teaches GPCs." Citing one practice in SWI that you (incorrectly) think is not about GPCs cannot be taken as evidence that GPC instruction might not be addressed in some other part of SWI practice. That seems like an error in logic that should have been caught in the review process.

It is also noteworthy that this same review process made no effort to confirm the validity of your dramatic claim about SWI. Any literacy instruction in English that failed to explicitly teach about grapheme-phoneme correspondences would be worthy of ridicule. Surely, the review process should confirm the validity of such a damaging claim before publication. At the very least, it should correct the record after being alerted to the error.

\section{Evidence countering your claim re SWI and GPC's}

Googling "structured word inquiry" brings one to many sources including my website for educators and my related YouTube page with countless illustrations of explicit instruction about grapheme-phoneme correspondences in SWI. All of my published research that cites SWI emphasizes the instruction of grapheme-phoneme correspondences (Anderson, Whiting, P. Bowers, Venable, 2019; J. Bowers \& P. Bowers, 2017, 2018a, 2018b; P. Bowers \& Cooke, 2012; P. Bowers \& Kirby, 2010; Kirby \& P. Bowers, 2012, 2017, 2018).

\section{Spelling-out-loud the orthographic structures of words in SWI explicitly targets grapheme-phoneme correspondences}

I assume you intend your phrase 'spell words out' to refer to the practices I call "spelling-out-loud," (done orally, without writing) "writing-out-loud" (done orally in concert with writing) and also the more general "spelling-out orthographic structure."

Regardless, this practice is not simply about naming the letters of a word from left to right as you imply.

The intervention study (P. Bowers \& Kirby, 2010) that introduced the phrase "structured word inquiry" describes spelling-out-loud word sums as a means of explicit instruction about grapheme-phoneme correspondences. We wrote:

...[S]tudents were taught to spell out word sums both in writing and orally to emphasize morphemic and graphemic units. Thus the word sum please/ + ure $\rightarrow$ pleasure was modeled on an overhead transparency as the class and teacher simultaneously wrote and spoke out loud, " $\mathrm{p}-\mathrm{-}-\mathrm{l}-\mathrm{-e}-\mathrm{a}-\mathrm{-}-\mathrm{s}-\mathrm{-e}-\mathrm{plus}$-u-r-e--is re-written as--p--1--e-a--s--no e-u-r-e". The dash length represents pause length between saying letter names. For this word sum, a long pause indicates the morphemic boundary between the base and the suffix. The letter names in the $e a$ string are named together quickly to highlight its structure as a digraph. (p 526) 
Clearly there is no reason to highlight graphemes without linking them to the phonemes they represent. The article goes on to describe how the intervention explicitly addressed the morphophonemic nature of English by showing that morphemes with consistent spellings can have multiple pronunciations. The grapheme-phoneme correspondences of the <ea $>$ digraph and the $<\mathrm{s}>$ graphemes in the morphological relatives "please" and "pleasure" were key to the selection of this morphological family for instruction. These words and others represented by the matrix from the study (see Figure 1) help reveal how spelling works in our morphophonemic system. These are common, familiar words with clear meaning connections. The matrix establishes the written morphological structure as a context in which to study common grapheme-phoneme correspondences. For example, the varied pronunciations of the $<$ ea $>$ digraph in the morphological relatives "please" and "pleasure" illustrate how graphemephoneme choice is constrained by morphology. Since spelling represents morphology more consistently than phonology, it requires graphemes that can represent many phonemes. It's not a "bug" that there are so many ways to spell the "sounds" in English; it's a feature. The interrelation of morphology and phonology is essential to understanding (not memorizing) the spelling of these words.

To better understand how SWI teaches grapheme-phoneme correspondences, you'll want to see more on this aspect of SWI instruction from this family in Figure 1 and additional detail and commentary in this video. To be clear, that video does not address the topic of early SWI. It simply uses the morphological family of $<$ please $>$ to clarify distinctions between isolated phonics and instruction that explicitly show how morphology can influence grapheme-phoneme choice.

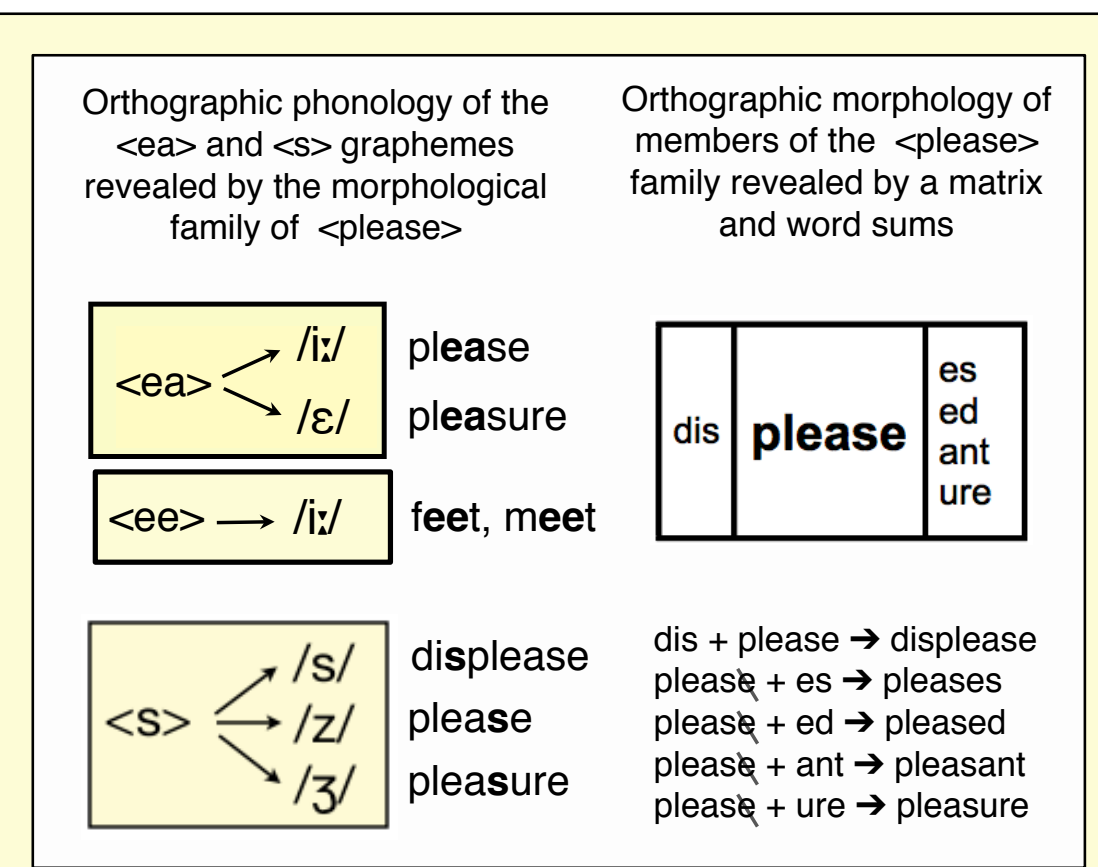

Figure 1: Orthographic concepts explicitly taught through the morphological family of $<$ please $>$ with matrices, word sums and grapheme-phoneme charts using IPA. Note the juxtaposition of the grapheme-phoneme diagrams for the $<$ ea $>$ and $<$ ee $>$ digraphs. During the intervention, I showed that the word "please" could not be spelled $*<$ pleese $>$. Although it seems to work for the phonology of that one word, that spelling would not work for its morphological relatives like "pleasure" and "pleasant." A central lesson in SWI is that we can't understand spellings in isolation. It's not enough to know the possible grapheme-phoneme correspondences for the word "please," we need to find the graphemes that can represent any of the pronunciations of this base. The $<$ ee $>$ digraph can't do the job for this family -- the $<$ ea $>$ can. This family provides a particularly rich illustration of orthography. It is not just the $<$ ea $>$ digraph that represents various pronunciations of words in this family. We can use this family to teach three pronunciations of the grapheme $<_{\mathrm{S}}>$ also. 
Countless morphological relatives in the study could have been selected to illustrate the "spelling-out-loud" process in the article (e.g., sign/signal, do/does, act/action). But I wanted a base with at least one digraph or trigraph. Bases with only single-letter graphemes would not clarify that this process explicitly directs attention to graphemes, not isolated letters.

It is ironic that you chose the essential SWI practice of "spellingout-loud" (misquoted as "spell words out") as evidence that "contradicts any claim that SWI teaches GPCs." This practice explicitly targets instruction about what the available graphemephoneme correspondences are and how they work in our morphophonemic system. Please identify any source that mischaracterizes "spelling-out-loud" as you have or that suggests that the instruction of grapheme-phoneme correspondences is not essential to this practice or to SWI in general. I am concerned by any source misrepresenting structured word inquiry in this way.

Since that paper in 2010, I have placed more and more emphasis on this practice. I describe detailed conventions for "spellingout-loud word structure" (another term I use) on my website for educators and in this document.

\section{Examples of explicit instruction about grapheme-phoneme correspondences in SWI}

Below are just a few publicly available illustrations of explicit instruction about grapheme-phoneme correspondences in SWI, including how that instruction is presented within a morphological context - and where appropriate - with explicit attention to etymology.

See THIS VIDEO (2011) titled "Investigating graphemes in Grade 1." Throughout the video we see the teacher, Skot Caldwell, and his students investigating digraphs and trigraphs and associating them with phonemes they represent. We also see how the lesson incorporates the process of "spelling-out-loud" and "writing-out-loud" morphological and graphemic structures.

This video (2012) models how spelling-out orthographic structure can be used in a response to a student's question about why "school" has an $<\mathrm{h}>$ in it. I show spelling-out word structure for teaching grapheme-phoneme correspondences and assessing student understanding of those correspondences.

This video (2016) shows Sam Modest, a Grade 2 teacher walk the viewer through investigations about grapheme-phoneme correspondences in his class. As Sam points out, this work built directly on Lyn Anderson's practice (Beyond the Word). I shared this video of Lyn modeling a similar approach for an investigation for the orthography of the /f/ phoneme in 2010.

This video from December 2019 is titled "Structured Word Inquiry (SWI) and grapheme-phoneme correspondences." It provides a model of an SWI session with a focus on graphemephoneme correspondences within a morphological frame.

\section{SWI provides more explicit instruction of grapheme- phoneme correspondences than is practiced in phonics}

Clearly your assertion that there is no basis for "any claim that SWI teaches GPCs" is false. In the interest of scientific accuracy, I trust that you will endeavour to correct this mischaracterization both in research and social media contexts.

In addition, given common misunderstanding and misrepresentation about SWI, I use this public letter to show that far from undermining instructional attention on graphemephoneme correspondences, SWI provides more explicit instruction about this topic than is possible according to any 
published definition of phonics I have seen. This may seem like a bold claim, so let's consider the evidence.

At its most basic level, SWI is simply word-level literacy instruction that uses scientific inquiry as a means to teach how our English spelling system works. A premise that guides SWI is that instruction should accurately reflect the content being studied. Of course this is not a radical hypothesis. For example, this straightforward idea was expressed by Rayner, Foorman, Perfetti, Pesetsky, and Seidenberg (2001), who argued that becoming literate means "learning how to use the conventional forms of printed language to obtain meaning from words." It logically follows that "the child learning how to read needs to learn how his or her writing system works" (Rayner et al, p. 34).

Educators and literacy researchers who accept this premise should feel obliged to interrogate how well the instruction they support reflects what we know about how our writing system works. Richard Venezky offered a key starting point for making sense of how English spelling does and does not work,

English orthography is not a failed phonetic transcription system, invented out of madness or perversity. Instead, it is a more complex system that preserves bits of history (i.e., etymology), facilitates understanding, and also translates into sound. (1999, p. 4)

English orthography has evolved to represent the interrelation of morphology, etymology and phonology (N. Chomsky \& Halle, 1968; C. Chomsky, 1970; Venezky, 1967, 1970, 1999; Pinker, 1999). This is not a recent interpretation from SWI. It is the established linguistic understanding upon which SWI bases its instruction.
Since SWI strives to ensure that literacy instruction is consistent with our best understanding of how English spelling works, a necessary feature of SWI is to teach how orthography represents English phonology. This requires instruction for two aspects of grapheme-phoneme correspondences in English:

1) what the available grapheme-phoneme correspondences are;

2) how grapheme-phoneme choice in English is guided by morphological and etymological considerations.

It is this second point that justifies the argument that SWI provides more explicit instruction about grapheme-phoneme correspondences than is possible in phonics. The definition of "systematic phonics" in your article provides a representative definition of phonics and supports my argument.

You write,

The term 'systematic phonics' describes practices for teaching decoding and word reading. It teaches students the correspondences between graphemes (letters and letter clusters) in written words and phonemes (speech sounds) in spoken words, and how to use these grapheme-phoneme correspondences to read and spell. Phonics instruction is systematic when it teaches the major grapheme-phoneme correspondences in a planned sequence. (Buckingham, 2020, p. 2)

As is true of every published definition of phonics that I have read, you make no mention of morphology or etymology. Thus, this definition of phonics instruction does not include any guidance or recommendation for teaching how these features of language delimit grapheme-phoneme choice. 


\section{Terminology: "isolated phonics" vs. instruction about "orthographic phonology"}

Essentially, the term "phonics" has long been the only term used to describe "instruction about grapheme-phoneme correspondences." This may lead some to falsely conclude that, since SWI does not mention "phonics," it must not teach about grapheme-phoneme correspondences. As your definition shows, "systematic phonics" addresses grapheme-phoneme in isolation from morphological and etymological influences. Thus, according to the established definition, "phonics" cannot be used to describe how grapheme-phoneme correspondences are taught in SWI. Educators and researchers need precise terminology that distinguishes qualitative differences in the nature of instruction.

For clarity, then, I use the phrase "isolated phonics" to refer to your definition of "systematic phonics," which relies on explicit instruction about grapheme-phoneme correspondences without reference to morphology or etymology.

By contrast, SWI teaches "orthographic phonology": the conventions by which orthography represents phonology in English. Thus, orthographic phonology as taught in SWI involves explicit instruction about what the available graphemes are (which isolated phonics can address) but also about how those correspondences operate in our orthography system (which isolated phonics can't address). Studying a set of words may clarify the concepts behind this terminology.

As illustrated with the $<$ please $>$ morphological family, in English, grapheme-phoneme choice is driven by a spelling system that favors consistent spelling of morphemes (bases and affixes) over consistent spelling of phonemes. This does not make the $<$ please $>$ family special. It is just a reflection of how English orthography works. Consider the pronunciation of the morphological structures linking the following word pairs.

(Word sums at right make their morphological structure explicit.)

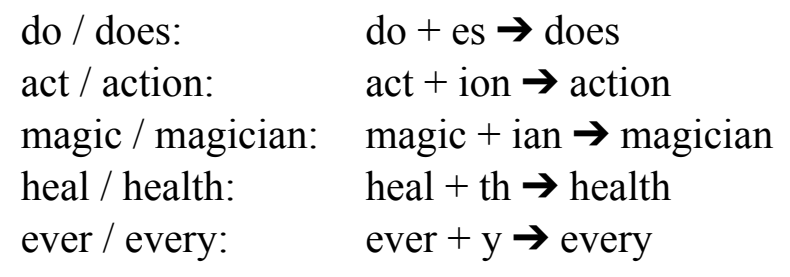

Notice that in each case the base or stem ${ }^{1}$ can be identified by a spelling but not by a pronunciation.

I consider two of these examples in detail to illustrate how SWI teaches (1) what the grapheme-phoneme correspondences are and (2) how they work in our morphophonemic system.

\section{SWI uses the word "does" as an illustration of the logical way English spelling works to represent the interrelation of morphology and phonology}

Imagine a child struggling with the grapheme-phoneme correspondences in this word. They may misread the word or misspell it (e.g., $*<$ duz $>$ ). Isolated phonics cannot explain the grapheme-phoneme correspondences of this word. Thus it treats "does" as an "exception" or a "sight word" children have to memorize because it doesn't follow the grapheme-phoneme correspondences that isolated phonics teaches. Teachers who understand how English orthography works -- with the help of

\footnotetext{
1 In morphology, we can use the term "stem" to refer to a complex structure comprised of a base and at least one other element to which another morpheme is to be added. The word "magic" has the structure <mage/ + ic $\rightarrow$ magic $>$. To study the orthographic phonology of the <c> grapheme in the words "magic" and "magician," there is no need to analyze "magic" fully. The term "stem" lets us refer to this complex structure without misrepresenting it as a base.
} 
tools like the matrix and the word sum -- can explain this spelling to students.

Studying the structure of this word and some of its morphological relatives alongside the $<$ go $>$ family, which has a similar structure, allows us to understand these spellings (see Figure 2).

There is nothing irregular about the $<_{0}>$ grapheme representing the /u:/ phoneme in "do" (e.g., "to" and "move") and the $/ \mathrm{N}$ phoneme in "does" (e.g., "come" and "son"). Since the $<_{\mathrm{s}}>$ grapheme is the most common way to spell the /z/ phoneme, there should be no reason to expect "does" to be spelled with a $<\mathrm{z}>$. If we use a word sum to show the $<$-es $>$ suffix in this word, we can explain why we cannot use $<\mathrm{z}>$ for $/ \mathrm{z} /$ in this word. The spelling $<$ does $>$ reflects the orthographic phonology of this word and its relatives perfectly. It uses the available graphemephoneme correspondences that can mark the morphemes with consistent spelling despite differing pronunciations.

Those who emphasize the importance of early explicit instruction about grapheme-phoneme correspondences should have a keen interest in the fact that instruction about orthographic phonology in SWI explains the grapheme-phoneme correspondences in such a common, early word as "does" while phonics cannot.
Far more importantly, however, SWI uses the spelling of "does" to help learners make sense of the ordered way the English spelling system works in our morphophonemic language. The principles that drive the spelling of "does" make sense of countless words that isolated phonics cannot explain. Any parent or teacher knows the frustration struggling readers experience with so many "sight words" that don't conform to the "lettersound correspondences" they are taught.

Dyslexics demonstrate daily that they are bad at memorizing spellings. Without addressing the interrelation of morphology and phonology, isolated phonics teaches struggling kids to memorize "irregular" spellings. By contrast, SWI uses those same spellings to explain the logical order of English spelling.

In addition, working with matrices and words sums ensures that students and teachers study words that share the same base. This means that instruction about grapheme-phoneme

correspondences in related words is always done with attention to the meaning connection between those words. Thus children learn the abstract grapheme-phoneme correspondences in words like "do" and "does" bound to meaning and structure cues that are absent in isolated phonics.

For more on this binding of orthographic, phonological and semantic features of words, which is explicitly targeted in SWI but not in isolated phonics, see our "Binding agent theory of morphological knowledge" (Kirby \& P. Bowers, 2017), which builds on Perfetti's Lexical Quality Hypothesis (2007) and on cognitive load theory (Schnotz \& Kürschner, 2007). Also see the discussion in J. Bowers \& P. Bowers (2017) on the longestablished psychological findings of the importance of meaning for encoding memories (e.g., Bower et al., 1969; Craik \& Tulving, 1975; Konkle, Brady, Alvarez, \& Oliva, 2010). 


\section{The spelling of <action>: A context for contrasting explicit instruction about grapheme-phoneme correspondences in "systematic phonics" vs. "orthographic phonology" of SWI}

I encourage readers to draw on your definition of systematic phonics to explain the grapheme-phoneme correspondences in the word "action." The reader no doubt perceives the $/ \int /$ phoneme (often referred to as the "sh sound" in phonics). What grapheme in <action> represents that phoneme?

I have seen many phonics-based resources identify $*<\mathrm{ti}>$ as a digraph representing this phoneme in words like "action" or "station" and others.

It turns out that morphological analysis with a word sum conclusively rejects this hypothesis:

$$
\begin{aligned}
& \text { act }+ \text { ion } \rightarrow \text { action } \\
& \text { state/ }+ \text { ion } \rightarrow \text { station }
\end{aligned}
$$

An inherent feature of graphemes is that they occur only within morphemes. No grapheme ever crosses a morphemic boundary. We can see those boundaries clearly when we use word sums to analyze the morphological structure of words. This crucial fact about grapheme-phoneme correspondences cannot be addressed by isolated phonics, which makes no reference to the morphological structure in which graphemes are found.

So how can explicit instruction about grapheme-phoneme correspondences explain the spelling <action $>$ vs. ${ }^{*}<$ acshun $>$ ?

The "4 Questions of SWI" (next page) provide guidance. They remind us to ensure that we are clear on the meaning of the word "action" before drawing any conclusions about the graphemephoneme correspondences in this word. In this case, I might talk

\section{More terminological trouble: The "z sound"}

It is a common practice in phonics to refer to "phonemes" by letter names. For example, the /z/ phoneme is often called the " $z$ sound." It is true that when the $/ z /$ phoneme is initial in a word, it is written with the $<_{\mathrm{z}}>$ grapheme. But by far the most common way to write the $/ \mathrm{z} /$ phoneme is the $<\mathrm{s}>$ grapheme! Thus, most of the times when a student notices a $/ \mathrm{z} /$ phoneme, they have to ignore the explicit instruction of the "z sound" to spell or pronounce it accurately. Similarly, there is no $\langle t\rangle$ in words with the "t sound" like "jumped" and there is a $<t>$ in words like "action" where we hear an "sh sound."

SWI brings precision to instruction about grapheme-phoneme correspondences by using and explaining these terms from the beginning of instruction -- and not referring to phonemes by letter names.

about "action movies," which we can use to prompt students to think of words like "actor" and "acting."

Juxtaposing these related words, writing them out-loud, and pausing at the morphemic boundaries can help us with aspects of questions 2 and 3. In all three words, a teacher can spell out the base $<$ act $>$ as single-letter graphemes and then pause before announcing the letters of the suffixes together quickly to mark their nature as a unitary morphological structure.

The teacher can also present the written structure of these words with word sums as a hypothesis of the structure of <action> (Question \#2) and its relatives (Question \#3).

$$
\begin{array}{lll}
\text { act }+ \text { ion } & \rightarrow & \text { action } \\
\text { act }+ \text { or } & \rightarrow & \text { actor } \\
\text { act }+ \text { ing } & \rightarrow & \text { acting }
\end{array}
$$

Questions 2 and 3 guide teachers to what I describe as the "structure and meaning test," which is key to morphological analysis. (See Kirby \& P. Bowers, 2017 and this video for more 


\section{Found an interesting word?}

1. What is the sense and meaning of your word?

2. How is it built?

$\downarrow$. Can you identify any bases or affixes with a word sum?

3. What related words can you find?

- Morphological relatives: Look for words that share a base. - Etymological relatives: Look for words that share an historical root.

4. What graphemes function coherently here?

- Check that they represent the phonemes across the morphological family. - Check the influence of word origin on grapheme choice.

- Is what you thought was a grapheme actually an orthographic marker?

\section{Peter Bowers, 2019
WordWorks Literacy Centre}

on this topic.) This phrase describes the fact that, in order to conclude scientifically that two words share the same morphological base in present day English, two criteria must be met:

The structure test: The proposed morphological relatives can be analyzed with a coherent word sum to link the words with the same spelling of the base ${ }^{2}$.

The meaning test: The proposed morphological relatives must derive from the same historical root. The meaning connection between the words is not just any kind of meaning -- but meaning that derives from the etymology ${ }^{3}$.

Neither of these tests is sufficient on its own. Although one may not feel the need to test the etymology in words like these, as the meaning and structure connection are so clear, it is not difficult to search the etymology using a reference like Etymonline.com to show that all these words go back to the same historical Latin root agere, actus for "do, perform."
With these word sums confirmed, we can safely construct a matrix. Add a few more morphological relatives to build a matrix like the one shown in Figure 3. In the family of the word "action" the role of morphology is particularly clarifying for understanding the grapheme-phoneme correspondences. The $<$ sh $>$ digraph would work only if its base were always pronounced with a $/ \int /$ phoneme.

Of course, as a word on its own or in words like "acting" or "actor," the base $<$ act $>$ is pronounced with a $/ \mathrm{t} /$ not a $/ \mathrm{J} /$ phoneme. The $<\mathrm{t}>$ grapheme can represent the orthographic phonology of this whole word family. The $<$ sh $>$ digraph cannot. (We saw this same morphological constraint on grapheme choice with the $<$ ea $>$ in the base $<$ please $>$.)

It should be of keen interest to those who emphasize the importance of grapheme-phoneme instruction to discover that SWI teaches a common grapheme-phoneme correspondence $(<\mathrm{t}>$ for $/ S /$ ) that I have yet to see described in phonics. Not only does SWI provide more explicit instruction of grapheme-phoneme correspondences, it teaches some common ones isolated phonics fails to address or addresses inaccurately. By inaccurately I refer specifically to faulty "explanations" that do not reflect the coherence of the English writing system.

Without referencing morphology, isolated phonics instruction forces learners to memorize grapheme-phoneme correspondences that SWI can help students understand. See illustrations of Grade $1 \mathrm{SWI}$ instruction addressing these concepts (Figure 4, next page).

2 By "coherent" I mean that all morphemes in the word sums are known morphemes in other words and that all suffixing conventions are appropriately applied.

3 The words "fast" and "quick" may have similar meanings, but they would not pass this "meaning test" as they do not share a historical root. 


\section{SWI teaches both phonology and morphology in ways that reveal the coherence of the English writing system}

Because morphology is a key part of SWI, it is often framed as "morphological instruction." It is certainly fair to include SWI in studies looking at the effect of morphological instruction since the requirement of such studies is that they include a significant amount of morphological instruction.

Nonetheless, describing SWI as "morphological instruction" is misleading in profound ways. This characterization ignores the phonological and etymological content of SWI. It also falsely implies that SWI teaches morphology as though it is "isolated morphology." When teachers using isolated phonics instruction add isolated morphological content, it misrepresents morphology by failing to show how morphology interacts with phonology and etymology. SWI is not only morphological instruction or only phonological instruction: it is simply orthographic instruction -- instruction about how English orthography works.

The main area of controversy in the research regarding SWI is the proposal that instruction should address the interrelation of morphology, etymology and phonology from the beginning of instruction (J. Bowers \& P. Bowers, 2017, 2018a). One thing that needs to be made clear before addressing this issue is that I have always emphasized that because there are few studies on SWI so far, findings are only preliminary regarding SWI with early literacy or with any age or ability. As we have noted:

In contrast with the vast amount of empirical research on phonics, the research on SWI is only beginning. Nevertheless, we would argue that the theoretical motivation for SWI is extremely strong" (J. Bowers \& P. Bowers, 2017, p. 138)

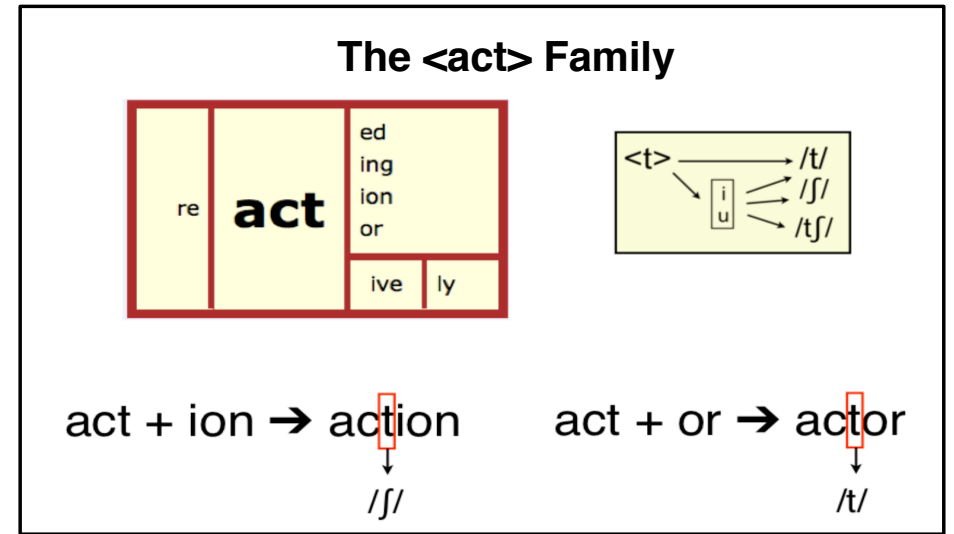

Figure 3: A representation of how English orthography reflects the interrelation of morphology and phonology in the <act> family using a matrix, word sums and IPA to mark grapheme-phoneme correspondences.

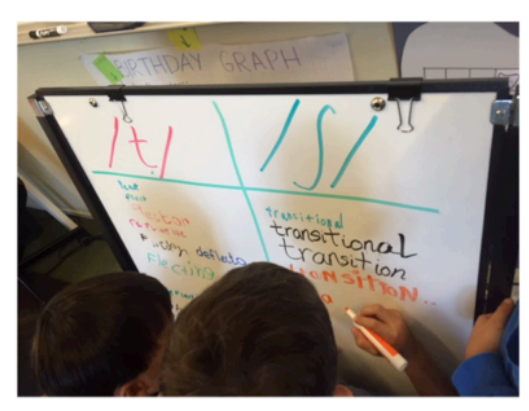

Write a couple word sums from this matrix. Remember the vertical (up and down) lines tum into plus signs in a matrix.
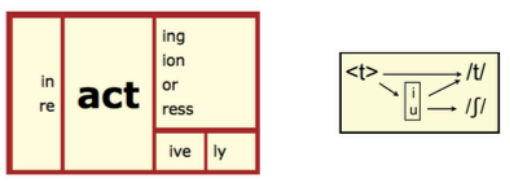

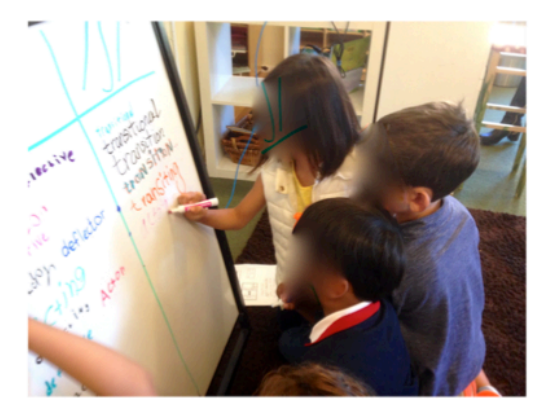

Write a couple word sums from this matrix. Remember the vertical (up and down) lines turn into plus signs in a matrix

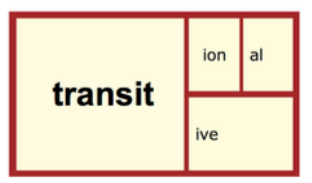

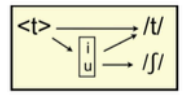

Figure 4: Grade 1 students explore the orthographic phonology of the grapheme $\langle t\rangle$ with the help of morphological relatives, matrices and word sums. Click HERE for a document with these images and a lesson used to guide students in constructing this matrix. 
In our view, a key priority for reading research is to directly compare phonics with SWI or other approaches to reading instruction that emphasize the fact that word spellings are organized by phonology and meaning." (J. Bowers \& P. Bowers, 2018a, p. 5)

These are not strong claims about the effects of SWI instruction at any age. They are claims that the evidence we have should motivate careful testing of the effects of instruction about the interrelation of morphology, etymology and phonology for students of all ages and abilities.

A recent intervention (Georgiou, Savage, Dunn, P. Bowers, Parrila, 2021) provides an early step in this direction. We randomly assigned 48 persistently poor Grade 3 readers with previous intensive phonics instruction to three conditions: SWI, a Phonics intervention with related word identification, spelling and meaning-based activities, and a no intervention Control. Neither intervention had significant effects on word reading (measured by WRAT scores) compared to Controls, although the children with stronger morphological awareness before the intervention did gain significantly in word reading in both conditions. Perhaps earlier explicit morphological instruction would have benefited both groups. One advantage SWI had over the Simplicity condition was that word reading effects increased from post-test to a 3 months delayed post-test but decreased over time for the Simplicity condition. Those findings are in line with the hypothesis that the deeper processing of multiple features of lexical quality in SWI should yield richer, well-integrated mental representation of schema. Note that SWI showed no disadvantage compared to the Simplicity condition, and that morphological knowledge was a benefit to both groups. This counters the common fear that time spent on morphology will harm learning for less-able students due to reduced time for phonics.

A fair challenge about SWI is its demand for linguistic knowledge for teachers and students. It may be that longer interventions and more intensive training for interventionists are needed for larger effects of SWI to be observed. Note that we have decades of research and practice refining isolated phonics practice. We can predict more room to grow with SWI as we are at the very beginning of learning how best to teach SWI.

\section{Morphological instruction and the research}

Research on morphological instruction is not the same as research about SWI instruction. But evidence about morphological instruction provides clear motivation for testing the effects of SWI. A look at the research reveals a decades-long focus on isolated phonics instruction coinciding with an underemphasis on morphological instruction. This is especially true regarding instruction with younger and less able students.

In her influential book, Beginning to Read, Adams (1990) argued that "although teaching older readers about the roots [morphological bases] and suffixes of morphologically complex words may be a worthwhile challenge, teaching beginning or less skilled readers about them may be a mistake" (Adams, 1990, p. 152). The focus of this book was to compare evidence for phonics and whole language instruction with less explicit phonics instruction. Morphology was not a central topic of Adams's book. She did not claim research evidence for her view, she simply presented it as a hypothesis. 
A decade later the National Reading Panel (2000) and the major review by Rayner et al. (2001) that I cited earlier made no mention of the need to test the effect of morphological instruction. Adams's decade-old claim was treated as though it was empirically based, but there was no evidence from instructional studies to support or contradict her speculation.

A decade after those reviews and two decades after Adams's hypothesis, we finally had enough morphological interventions to study in meta-analyses (P. Bowers, Kirby \& Deacon, 2010; Goodwin \& Ahn, 2010, 2013) and reviews (Reed, 2008; Carlisle, 2010). These studies all found morphological instruction was beneficial in general. Further, and in direct contrast to Adams's hypothesis, they all corroborated the finding that younger and less able students gained the most from the inclusion of morphology in literacy instruction.

One might have expected a fairly dramatic response from the research community when preliminary findings from all relevant studies directly contradict assumptions that have guided the literacy research for decades.

While this finding may have surprised many, it should have been received as good news for researchers looking for ways to improve literacy instruction. Consider this conclusion from Al Otaiba and Fuchs (2006).

In light of our findings and study limitations, there is a need for continued research to address the needs of children who do not respond to scientifically based classroom (or primary-level) instruction. Our nonresponders clearly required a secondary level of intervention, using a different method or combination of methods delivered with greater intensity than was available to our study participants. (Al Otaiba \& Fuchs, 2006, p. 428)

They made no mention of morphology. When meta-analyses and reviews on morphological instruction were finally available, the findings pointed directly at what Al Otaiba and Fuchs (2006) were looking for but had not considered.

Given that phonological deficits are associated with literacy difficulties, perhaps morphological instruction brought particular benefits to struggling students because it allowed them to leverage unimpeded cognitive processes. And since English is a morphophonemic system in which grapheme choice is constrained by morphology, perhaps morphological instruction would bring benefits to phonological learning that are not available from isolated phonics.

Findings from Goodwin and Ahn's two meta-analyses of morphological instruction - one for students with learning disabilities (2010) and one for students in general (2013) support this hypothesis. The researchers' calculated effect sizes for outcomes from the morphological interventions in their studies are presented in Table 1. (See next page.)

Notice that the greatest effect sizes from morphological instruction were found for phonological outcomes. In all but one case (decoding outcomes for less able students) phonological outcomes had greater effect sizes than did the morphological outcomes. Explaining this result, they wrote:

Similar to Bowers et al. (2010), results suggest that early morphological instruction may be particularly helpful perhaps because of the synergistic relationship between phonology and 
morphology and the larger repertoire of root [base] and affix meanings available for use. If a reciprocal relationship exists between morphological knowledge and literacy...it makes sense to jump start this knowledge from an early age" (Goodwin \& Ahn, 2013, p. 23).

\begin{tabular}{lcc} 
& \multicolumn{2}{c}{ Effect size } \\
\hline Outcome & $\begin{array}{c}\text { Goodwin \& Ahn, 2010 } \\
\text { Literacy difficulties }\end{array}$ & $\begin{array}{c}\text { Goodwin \& Ahn, 2013 } \\
\text { All students }\end{array}$ \\
\hline Phonological awareness & 0.49 & 0.48 \\
Morphological knowledge & 0.40 & 0.44 \\
Phonological recoding & 0.54 & $*$ \\
Decoding & 0.23 & 0.59 \\
Spelling & 0.20 & 0.30 \\
Vocabulary & 0.40 & 0.34 \\
Fluency & -0.28 & -0.05 \\
Reading comprehension & 0.24 & 0.09 \\
\hline
\end{tabular}

* Not analyzed

Table 1: Effect sizes by outcome for meta-analyses of the effect of morphological instruction (Goodwin \& Ahn, 2010, 2013)

And yet many researchers continue to claim -- in direct contrast to the best current evidence from all the meta-analyses of morphological instruction -- that morphological content should be held off for some later (unspecified) amount of time.

We share Bowers and Bowers' (2018) view that an understanding of morphology simplifies the English lexicon, and that emphasis on these spelling-meaning regularities is likely to be an important part of reading instruction. However, we believe that such instruction is likely to be most fruitful later in reading acquisition, when children's text experiences allow self-teaching through generalisation of this knowledge. (Rastle \& Taylor, 2018, p 1504 )
[W]e would predict that the benefits of explicit morphological instruction are more likely to be observed somewhat later in reading development. (Castles, Rastle \& Nation, 2018, p. 25)

It is misleading to publish these "beliefs" and "predictions" without referencing the best available data which challenges their hypothesis. To be clear, hypothesizing that some amount of phonological instruction should precede morphological instruction is not the issue. The problem is doing so without reference to the long-available published data about the effects of morphological instruction for younger and less able students.

It is important to note that few studies have investigated the effects of morphological instruction with young children. Decades of recommendations from researchers against early morphological instruction (without evidence from instructional studies) have surely contributed to this situation. Clearly this gap in the research needs to be addressed before any strong conclusions can be drawn. Given the current evidence, the same hypothesis expressed in the quotes above can be presented in a far more constructive way with an argument such as this:

The evidence from meta-analyses shows particular benefits from morphological instruction for younger and less able students in ways that were not predicted from previous research. Given that evidence, we expect that some sort of morphological instruction could be beneficial much earlier than was previously thought.

However, in contrast to Bowers \& Bowers, we still hypothesize that the most effective literacy instruction would begin with phonics and introduce some sort of morphological content soon after. This hypothesis needs to be tested through experiment, not simply accepted as a default assumption. 
The statement above presents the same hypothesis as Rastle and colleagues, but acknowledges the best current evidence on the topic. And unlike their quotes, it is an explicit call for more research on this question.

Positive findings about early morphology instruction should be seen as an area of rich potential even though those findings come from a few studies. Researchers have been refining early literacy instruction based on isolated phonics for decades. As Al Otaiba \& Fuchs (2006) point out, many learners clearly need some other sort of instruction, but we must be near the ceiling for innovation of isolated phonics. By contrast, we are near the floor in terms of testing approaches to morphological instruction at any grade level. The fact that our early attempts have resulted in positive outcomes is a good sign of room to grow.

While I seem to be in the minority of researchers on this point, I see little basis for the argument that one has to teach graphemephoneme correspondences before introducing morphology. Berko (1958) showed that 4-year-olds have oral morphological knowledge. Clark (1985) described children creating derivations like "flyable." This kind of innovative morphological

experimenting with words is not a surprise to anyone who knows young children. Why not use morphological families -- at least in the oral domain -- as a context in which letter names and grapheme-phoneme correspondences can be taught?

In this video, we see Carolee Fucigna teaching about words from the family of the base $<$ rain $>$ with her pre-schoolers. Some of these students are still learning letter names while others are reading. What reasoning (and substantiating evidence) would justify waiting until students learn an arbitrary number of grapheme-phoneme correspondences before we introduce morphology in this way? To be clear, I do not present this video as research evidence that including morphology from the beginning of instruction is more effective than teaching isolated phonics first. I present it simply as an illustration of the kind of instruction that warrants scientific investigation. Decades of recommendations against early morphological instruction means that few have any image of what such instruction could even look like. (For a detailed account of early SWI instruction see Anderson, Whiting, P. Bowers \& Venable [2019]).

Meta-analyses about morphological instruction do not provide direct evidence in support of structured word inquiry. In our meta-analysis (P. Bowers, Kirby \& Deacon, 2010) and in subsequent publications (Kirby \& P. Bowers, 2012, 2017, 2018), we argued that the best evidence indicates that morphology should feature in literacy instruction and that it is particularly important for younger and less able students. We emphasized that what we lack is research evidence for how best to teach morphology. Structured word inquiry follows the evidence by including morphology in literacy instruction - including instruction with younger and less able students. In addition, SWI offers novel approaches to integrating morphological and phonological instruction, which are available for testing.

Note that benefits for phonological outcomes cited by Goodwin and Ahn $(2010,2013)$ were from morphological instruction that rarely addressed the interrelation of morphology and phonology. In our meta-analysis (P. Bowers, Kirby \& Deacon, 2010) only 5 of the 22 morphological interventions addressed this interrelation in any way at all. It makes sense to hypothesize that phonological gains from morphological instruction would be expected to increase when the interrelation of morphology and phonology is taught explicitly. Word sums, matrices and the 
grapheme-phoneme diagrams illustrated earlier provide researchers with tools to draw on for such research.

New research has only added to the evidence countering longheld assumptions about the role of morphology for less able and younger students. Consider the findings from Galuschka, Görgen, Kalmar, Haberstroh, Schmalz \& Schulte-Körne (2020), in their study, "Effectiveness of spelling interventions for learners with dyslexia: A meta-analysis and systematic review." Contrary to what many researchers might expect, the authors "did not find that phonics instruction is more effective than morphological interventions in the early years of formal literacy instruction or for more severe spelling deficits" (Galuschka et al. 2020, p. 13). What they found instead was this: "Against our hypotheses, the efficacy of phonics interventions decreased with increasing severity [of students spelling deficits], whereas the efficacy of orthographic and morphological interventions increased with increasing severity" (Galuschka et al., 2020, p. 12). Although these findings may be surprising to many, as they were to the authors themselves, they shouldn't be unexpected, given the evidence from meta-analyses of morphological instruction.

Also consider the findings from a recent major review titled "Orthographic consistency influences on morphological processing in reading aloud: Evidence from a cross-linguistic study," published by Mousikou, Beyersmann, Ktori, JavoureyDrevet, Crepaldi, Zeigler, Grainger \& Schroeder, (2020). The section under the title "Educational Implications" speaks so directly to the issues discussed here that I am quoting it extensively:

There is general consensus that systematic phonics, that is, explicit instruction of the relationship between letters and sounds, is best practice for early reading instruction in English (see Castles et al., 2018). However, as it has been recently pointed out by Bowers and Bowers (2018), English is a morphophonemic system that evolved to jointly represent units of meaning (morphemes) and phonology (phonemes). In fact, English prioritizes the consistent spelling of morphemes over the consistent spelling of phonemes. Accordingly, it has been suggested that reading instruction in English should be guided by the logic of the English writing system (Bowers \& Bowers, 2017). Thus, it should be organized around morphology and phonology rather than just phonology. Our findings support this idea. We found that developing readers of English made extensive use of morphology in reading aloud. Furthermore, we observed that good readers were overall more sensitive to morphological structure than poor readers. Importantly, poor readers of English often exhibit phonological processing deficits, so these children might benefit even more by teaching methods that focus on optimal grain sizes of their writing system (i.e., morphemes), which would allow a more straightforward mapping between print and sound, in addition to an easy mapping between print and meaning. (Mousikou et al., 2020, p 12)

Multiple reviews and meta-analyses of morphological instruction find evidence that directly contradicts decades of recommendations from researchers. Not only does it bring greater benefits to younger and less able students; the evidence is that morphological instruction brings specific benefits to phonological learning. Thus, what we find supports the suggestion of Rayner et al. (2001) that children learning to read are best supported by instruction 
that helps them understand how their writing system works. This is exactly the premise of SWI.

\section{A look back, and common ground for a way forward}

It is clear that in direct contrast to your claim (Buckingham, 2020), SWI provides explicit instruction about graphemephoneme correspondences. Unfortunately, the journal in which you made this claim chose not to publish a correction on this point. I hope you will find a public way to do so.

The baseless assertion that SWI underemphasizes or avoids instruction about grapheme-phoneme correspondences is a common one. This open letter attempts to clarify that SWI actually teaches about key aspects of these correspondences that systematic (isolated) phonics cannot. Researchers should be motivated to investigate SWI as a potential means for improving instruction about grapheme-phoneme correspondences.

English orthography is an ordered system that has evolved to represent the sense and meaning of words to speakers of the language. One way this is achieved is by favouring consistent representation of morphemes over consistent representation of phonemes (Chomsky \& Halle, 1968). English requires a system in which most graphemes can represent multiple phonemes and in which most phonemes can be represented by multiple graphemes. Of course, this long-established nature of English orthography is true regardless of the instruction children receive.

It is telling that morphological instruction has been found to bring greater benefits to phonological outcomes than to morphological outcomes (Goodwin \& Ahn 2010, 2013). This finding reflects the impact our interrelated orthographic system has on literacy learning despite instruction which rarely explicitly addresses that interrelationship. The evidence is that instruction about one feature of orthography (morphology) has positive effects for learning about another feature (phonology). This finding is hard to reconcile with the isolated view of morphology and phonology that characterizes the vast majority of literacy instruction and research. This cross-domain effect, however, makes perfect sense in a spelling system built on the interrelation of morphology and phonology. Research into the effects of explicit instruction not just about morphology or phonology but how they interrelate should be a high priority.

The "isolated" view of orthography fostered by isolated phonics has costs that are hard to see until one gets a peek at the clarity provided by the matrix and word sums. These tools provide concrete representations of the orthographic structure of a morphological family that we can study while also attending to the shifting phonology of the morphemes used to construct those words. The fact that words in a matrix are connected in meaning ensures that this orthographic study occurs within a meaningful context. The matrix and word sums provide what cognitive load theory describes as a "worked out example" of complex information (Cooper and Sweller, 1987). The scaffolding provided by visual representations of complex information reduces the demand on working memory and facilitates the formation of well-integrated mental representation of schema learning.

\section{Spotlight on the matrix: A foundation to build on}

Some researchers, including Rastle and colleagues (Rastle \& Taylor, 2018; Castles, Rastle \& Nation, 2018; Rastle, 2019a,b) are skeptical about early morphological instruction, but champion the importance of teaching about the interrelation of morphology and phonology at some point in literacy development. 
Consider the following from Rastle (2019a):

Written language is typically viewed as an expression of spoken language, and this perspective has motivated approaches to understanding reading and reading acquisition. However, in this article, I develop the proposal that written language has diverged from spoken language in important ways that maximise the transmission of meaningful information, and that this divergence has been central to the development of rapid, skilled reading. I use English as an example to show that weaknesses in the relationship between spelling and sound can give rise to strong regularities between spelling and meaning that are critical for the rapid analysis of printed words. Rastle (2019a, p. 1).

In that same article Rastle uses a graphic representation of a morphological family of the word "develop" (See Figure 5) which approximates the matrix and word sums and is proposed for the same instructional purposes. Rastle writes,

$[\mathrm{T}]$ he challenge of learning the spelling-meaning mapping is dramatically reduced if the learner has an appreciation of how morphological relationships are expressed in the writing. This principle is illustrated in Figure 3. The first panel of the figure lists 15 unique English words; however, if the learner has an understanding of morphology, then these 15 words become variations of a single word. It is unlikely that these words would need to be learned in an item-specific manner, one at a time, because learning the meaning of one word assists learning the others." (Rastle, 2019a, p. 9).

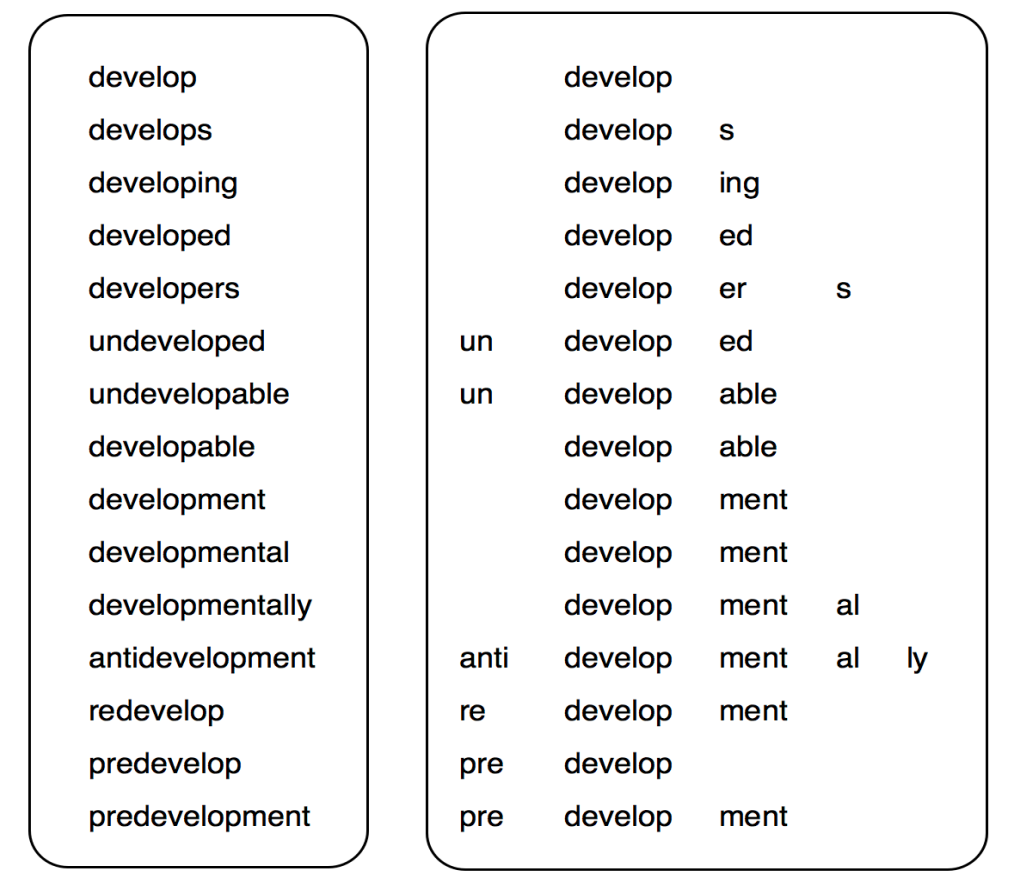

Figure 5: Reconstruction of Figure 3 in Rastle (2019a, p. 9) with a list of 15 members of the morphological family of the word "develop" on the left, and those same words with spaces to mark morphemic morphological structure.

Given her clear agreement with the theory and practice of SWI -- at least in non-initial literacy instruction -- it is odd that Rastle (2019a) makes no reference to it. With this position on the science, the logical response would be to draw attention to the research on SWI that supports her position for instruction, with the caveat that she recommends initial instruction should be isolated phonics. In fact the study that introduced the phrase "structured word inquiry" (P. Bowers \& Kirby, 2010) not only provided theoretical support for her argument, it also provided direct empirical evidence. 
In that study, Grade 4/5 students worked with matrices and word sums to investigate the interrelation of morphology, etymology and phonology including the suffixing changes and more. At post-test, students were tested on words in three categories based on level of transfer from instruction: "Word Taught," "Base taught" and "Affix taught." During the course of the 20 lessons over 4 weeks, students in the experimental group were exposed to 430 words either directly or simply because they were possible to construct from a matrix or word sum in any lesson. Those were labelled Word Taught words. Words that were never addressed in the lessons, but shared a base with words that were taught were labelled Base Taught Words. The furthest transfer category was Affix Taught words which had bases not addressed in instruction, but combined with affixes that were.

This design allowed us to test exactly the generative property of vocabulary learning proposed by Rastle (2019a). Results showed that the experimental group was better at defining Word Taught and Base Taught words, but not Affix Taught Words.

We used the matrix on the base $<$ sign $>$ from the intervention (Figure 6) to explain the nature of the generative vocabulary learning we found. This matrix represents approximately 18 words, making them Word Taught Words. Some of these words, like "signal," "signature" and "assignment," received the most explicit instruction because they were used to introduce key concepts that were central topics throughout the entire intervention.
Figure 6: Matrix for the base $<$ sign $>$. This matrix along with related word sums was used in the first lesson in the vocabulary intervention (P. Bowers, \& Kirby, 2010). We used it to describe the role of the matrix in that paper and in J. Bowers and P. Bowers (2017).

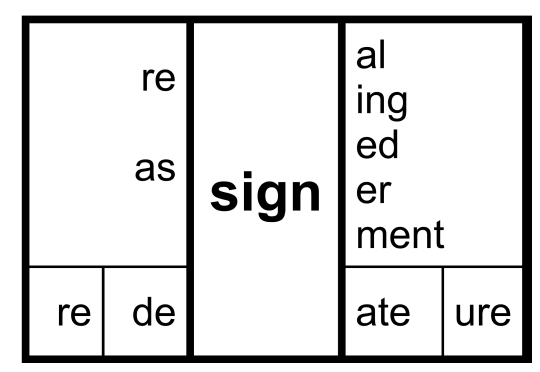

The word "insignificance" was in the post-test as a Base Taught word. It has the base $<$ sign $>$ from the Latin root signum for "mark, token," but it was not included in the matrix or any instruction. The experimental group was significantly better at defining Base Taught words like "insignificance" because they had been exposed to approximately 18 related words with varying levels of explicit instruction ${ }^{4}$.

As we wrote,

This instruction offered learners the rich active processing recommended by Beck et al. (2002) for 3 of the 18 words for the sign family while providing quick exposure to a larger number of words with the benefit of a structure and meaning referent to help 'map' new word meanings as recommended by Biemiller and Boote (2006)." (P. Bowers \& Kirby, 2010, p. 533)

Rastle (2019a) also hypothesized that instruction could use orthographic representations of the spelling-meaning link of morphological families to support generative vocabulary learning, and emphasized the need for empirical evidence.

${ }^{4}$ For another measure about identifying the base in these words, students in the experimental group were superior than controls for all three categories of words. The morphological instruction with matrices and word sums helped students identify bases of words they were not exposed to. Perhaps this represents an initial step towards better recognition of words with bases that are not explicitly taught. 
She wrote,

It seems plausible that limited morphological knowledge may act as a schema with which to interpret new words and conversely, that appropriately structured orthographic representations of these new words may further strengthen morphological knowledge.[Emphasis added.] In this way, knowledge of this feature of the writing system may support a form of morphological self-teaching that facilitates ongoing orthographic learning, as readers encounter increasingly complex derivations through their text experience. However, further computational modelling work is required to develop this proposal, and of course it is also subject to empirical evidence. [Emphasis added.] (Rastle, 2019a, p. 9)

For almost a decade, research about SWI has provided theoretical arguments, empirical data and instructional tools that directly support Rastle's (2019a) arguments. I am in complete agreement with her comments on using representations of orthographic morphological structure for instruction to strengthen generative morphological knowledge. The representation she uses (Figure 5) shares many characteristics with the matrix and word sums used in our study which provided empirical evidence for her hypothesis about morphology and word learning, but neither the matrix, nor those findings are referenced.

Rastle (2019a) describes the potential of an orthographic representation of morphological families for generative word learning. We presented just such a representation with matrices for $<$ do $><$ go $>$ and $<$ sign $>$ in J. Bowers \& P. Bowers (2017). Rastle (2019b) addressed our 2017 paper in detail, but did not mention the use of the matrix. Failing to cite previously used tools and evidence stifles discussion about refining instructional practice about an area of mutual agreement.

Rastle and I agree that it is important to teach about the orthographic structure of morphological families. Contrasting Rastle's representation with those used in SWI could provide a productive start to that discussion.

We recently conducted a study with adults to test the effect of the matrix on memory for words. (Ng, P. Bowers, J. Bowers, 2020). We compared three ways of presenting sets of words. One condition organized words by affix (e.g., <doing $>$, <going $>$, $<$ talking $>$, etc.). The second organized words around a base (e.g., $<$ doing $>$, $<$ redo $>$, $<$ undo $>$ ). The words in the control condition had no morphological relationship. The two morphological representations used a matrix-like presentation. Words in the control condition were presented in lists. We show that memory is better in both morphological conditions compared with a control condition. Most importantly, we showed that studying words in the base-centric format of the matrix improves memory over the affix-centric condition. This is a preliminary study about one feature of the matrix, but it provides guidance for further study. Both Rastle and P. Bowers and colleagues hypothesize that using representations of written morphological structure during instruction should support word learning (P. Bowers \& Kirby, 2010; J. Bowers \& P. Bowers, 2017; Rastle, 2019a). If this is true, exposure to the matrix should improve memory for words, and that is what we found. Also, as Ng et al. (2020) show, current morphological instruction is often organized around affixes rather than bases. Results from our study suggest morphological instruction is more likely to be effective when selection of words centres around bases rather than affixes, as is the case with both 
the matrix and Rastle's (2019a) representation of orthographic morphology.

Contrasting Rastle's representation of 15 morphological relatives of the word "develop" with a matrix that represents those same 15 words (and more) helps illustrate advantages of the matrix for learning and memory (See figure 7). Describing these advantages may encourage researchers to look more closely at the matrix and perhaps propose their own refinements to test.

In SWI, teachers and students discuss words they see in the matrix and then write-out-loud their underlying structure on the left side of a word sum, and the completed structure on the right. Here are three word sums that can be constructed from this matrix that are also represented in Rastle's representation:

$$
\begin{array}{ll}
\text { develop }+ \text { ing } & \rightarrow \text { developing } \\
\text { un }+ \text { develop }+ \text { ed } & \rightarrow \text { undeveloped } \\
\text { develop }+ \text { ment }+ \text { al } & \rightarrow \text { developmental }
\end{array}
$$

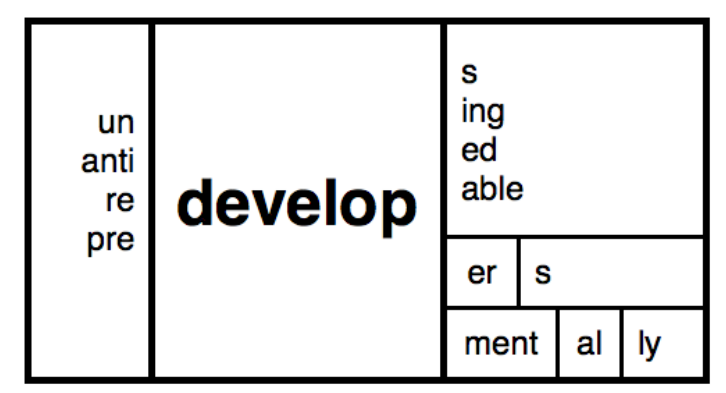

Figure 7: A morphological matrix for the morphological family of the word "develop." This matrix was constructed using only the morphemes in Rastle's representation. Word sums can be constructed from this matrix to represent the same 15 words Rastle's representation (See figure 5).
Although this matrix was constructed to represent exactly the morphemes and morpheme combinations of Rastle's representation, students and teachers can use it to identify words that were not in Rastle's list. Here are three possible examples:

$$
\begin{array}{ll}
\text { re }+ \text { develop }+ \text { ed } & \rightarrow \text { redeveloped } \\
\text { anti }+ \text { develop }+ \text { ment } & \rightarrow \text { antidevelopment } \\
\text { pre }+ \text { develop }+ \text { ed } & \rightarrow \text { predeveloped }
\end{array}
$$

One advantage of the design of the matrix is that, in contrast to Rastle's model, the matrix can use a single morphological representation for multiple words. For example, the matrix represents $<$ develop $>$ only once. The $<$-s $>$ suffix is the only morpheme that appears twice. This presentation dramatically reduces the text needed to represent Rastle's 15 words, and more.

When teachers and students use the "4 Questions of SWI" they are reminded to also consider etymological relatives. Searching the etymology of "develop" in a reference like Etymonline.com identifies its French root voloper for "wrap up."

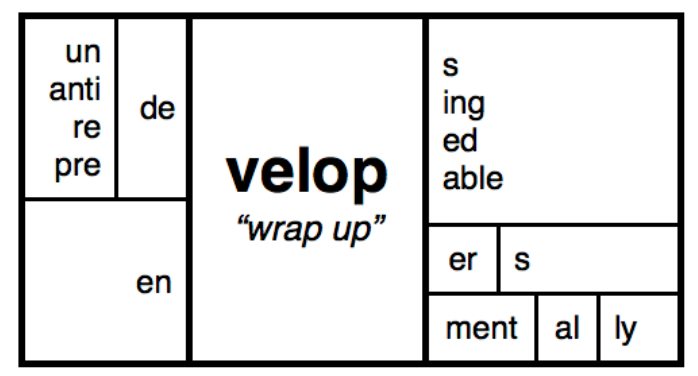

Old French root, voloper "wrap up"

Figure 8: Matrix with the bound base $<$ velop $>$ which represents all the words in the matrix for $<$ develop $>$ plus all the words that can be built the word "envelop" as well. Identifying the deeper structure links more words related in structure and meaning. 
That sense and meaning will be present to some degree in all the words derived from this root. Searching that root brings up the word "envelop" as it shares the historical root with "develop." This etymological cue can prompt new morphological analysis with word sums to show $<$ en- $>$ and $<$ de- $>$ prefixes can be removed from a bound base $<$ velop $>$. The words "envelop" and "develop" share a common historical root (meaning test).

Coherent word sums identify a common base spelled $<$ velop $>$ (structure test). This deeper analysis allows us to include "envelop" and many of its relatives (e.g., enveloping, enveloped, envelopment) to study in the revised matrix in Figure 8.

Especially for those new to SWI, this level of linguistic analysis may seem too advanced for students in the elementary years.

However, exactly these kinds of investigations are going on in countless classrooms around the world.

For just one example, watch this short video (screen shot below) of a Grade 5 student walking us through her study of the word "resistance" that she picked to investigate from studies about the French Resistance.

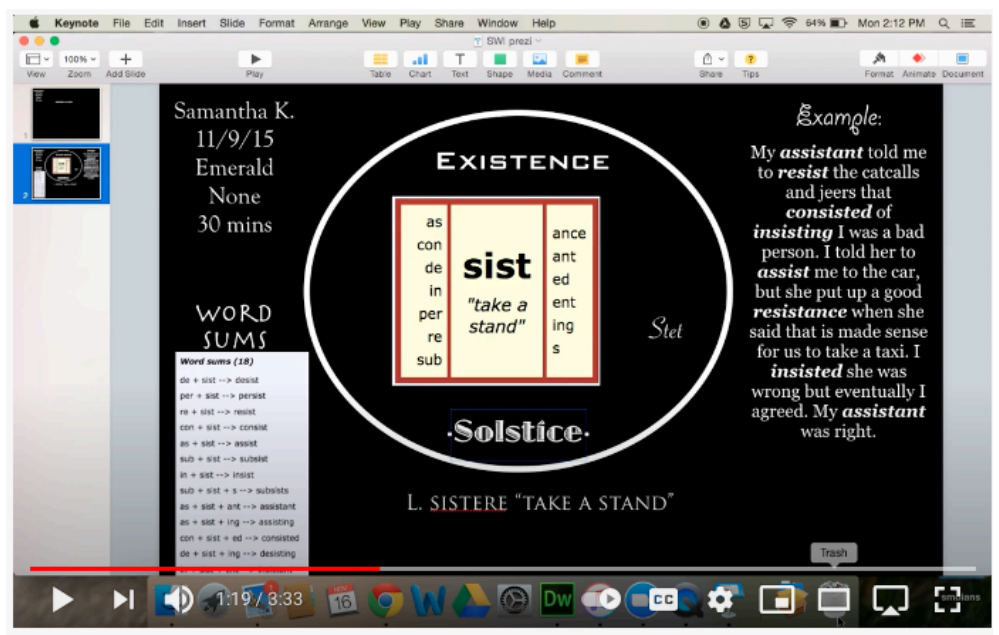

Watch as she models how she used etymological information from Etymonline to guide her in constructing a matrix on the base $<$ sist $>$ and many morphologically related words. Etymology also helped her identify some words with a different base, but the same root (in the oval around the matrix) and related meaning.

Investigating the spelling-meaning connections of words in this way, including working with the matrix, etymology and spellingout orthographic structure with word sums in SWI reflects multiple recommendations from cognitive load theory (Schnotz \& Kürschner, 2007). It allows students and teachers to explore the spelling-meaning relationships of whichever morphological combinations grab their attention without scrolling through a long list of every word. The practice of "writing-out-loud" word sums engages multiple motor-memory routes to help build wellintegrated mental representations of the spellings of the morphemes in this family. These written morphemes will be reencountered over and over and practiced in classrooms that work with word sums and matrices regularly.

Carlisle (2000) showed that shifts in phonology, orthography and semantics between morphologically related words hinder recognition of morphological relations. Instruction with the matrix and word sums (including practices for "writing out-loud" the suffixing changes) specifically addresses each of these features of morphological families. This explicit instruction can be expected to help students recognize morphological (meaningful) connections between words despite those shifts. It is not clear that Rastle's (2019a) representation targets all these same issues as explicitly. For example, given that none of the words in Rastle's representation of a morphological family involves spelling changes due to suffixing (Figure 5), it is unclear how her representation would represent this feature of 
morphology. In SWI the matrix shows the full form of every written morpheme, but word sums are used to study and reveal suffixing changes.

Also consider the role of etymology in expanding the bank of words in the study of words related to "develop" and in the student's investigation of the word "resistance." In both cases, identifying sense and meaning of the historical root of the target word also brought clarity to the semantic connections linking related words. In the video, we see the student's surprise in the word "solstice" coming up in her etymological search. But she is able to make sense of the connection to her original target word "resistance" when she has the sense and meaning from the common root sistere for "stand." To "resist" is to stand against. The summer "solstice" is when the sun stands at its highest in the sky. She cannot analyze "solstice" with the base $<$ sist $>$ found in "resistance" (re + sist + ance $\rightarrow$ resistance), so she correctly concludes they are etymological, but not morphological relatives. She shows that understanding by placing "solstice" in the "oval" around the matrix that is marked by the root.

A class studying the $<$ velop $>$ matrix might hypothesize that "developing an idea" is like wrapping up all the parts of that idea into a unified whole. The word "envelop" and the words it can build are more obviously linked to the idea of "wrap up" but that sense is not likely to come up if we only look at relatives built on the word "develop." It is this kind of unexpected discovery that so often grabs the attention of teachers and students working with the scientific inquiry of SWI and motivates on going study. These SWI practices engage students in the kind of deep semantic processing recommended for vocabulary learning (e.g., Beck, McKeown \& Kucan, 2002; Blachowicz \& Fisher, 2000). If we inspect the 15 words in Rastle's representation, there is little semantic distance between these words to provoke that kind of deeper semantic processing.

Repeated study like this can build up mental representations of the spelling of many morphemes, and how they bind to semantics and various possible pronunciations. (See more on binding theory of morphology in Kirby \& P. Bowers, 2017). As Perfetti's (2007) lexical quality hypothesis and cognitive load theory argue, higher quality lexical representations should facilitate automated access (reduced cognitive load) to lexical information during reading and writing. Like Rastle (2019a), Verhoeven and Perfetti (2011) highlighted morphological decomposition as a "self-teaching device in reading complex words via increasing lexical quality leading to instance-based learning of lexical items toward automatic recognition" (p. 461).

We can see a plausible virtuous cycle that grows from this kind of careful orthographic investigation. As Carlisle (2007) argued, "It is only when students believe they know how to analyze unfamiliar words in texts that they will expend the energy to become close readers" (p. 99). As Schnotz and Kürschner (2007) argued, students need meaningful tasks and motivation to form mental representations of schema because such learning is cognitively demanding. Rote learning of spellings (as is needed for sight words) is less likely to provide the motivation to develop such robust lexical representations. (For more on how SWI practice reflects recommendations of cognitive load see a detailed account here.)

The importance of teaching children specific skills for independent word learning has long been emphasized by researchers (e.g., Baumann, et al., 2002; Henry, 1988, 1989, 2003, Nagy, 2005; National Reading Panel, 2000; Pressley, Disney \& Anderson, 2007, Scott, 2005; Templeton, 2004). These 
examples also illustrate ways to build the "word consciousness" that Nagy and Scott (2004, p. 201) described as "the knowledge and dispositions necessary for students to learn, appreciate, and effectively use words."

The matrix and word sums are necessary tools for reliable scientific inquiry of orthographic structure, including understanding how grapheme-phoneme correspondences work in English. The matrix and word sum are required for the "structure and meaning test" that allow us to falsify hypotheses about which words are morphologically related. It was the word sum and matrix that showed us the phonology of the $<t>$ phoneme in $<$ action $>$ and falsified the $*<\mathrm{ti}>$ digraph.

However, despite growing interest in morphological instruction, very few researchers have drawn attention to the matrix and the word sum. The first citation in the research I know of was in Marcia Henry's (2003/2010) Unlocking Literacy. Despite the popularity of that book, the next mention of a matrix in a peer reviewed article of which I am aware was our SWI intervention (P. Bowers \& Kirby, 2010). I have included the matrix and word sum in every peer-reviewed publication about SWI including our recent intervention (Georgiou, et al., 2021). The only other citation of the matrix I know of in the research is in Murphy and Diehm (2020).

The good news is that regardless of differing views about when the interrelation of morphology and phonology should be taught, there seems to be a growing consensus that this is an important feature of literacy instruction that needs further study.

Few researchers are likely aware that teachers around the world have been experimenting for decades with the matrix, word sums and the practice of spelling-out-loud of morphemes and graphemes with students across a wide range of age and ability. This is one reason I've included many links to illustrations of this instruction in this open letter. This work offers researchers ideas they could study, adapt, test and compare to alternatives.

This brings us back to the original reason for this public letter to counter your false claim that SWI does not teach about grapheme-phoneme correspondences. Researchers and educators who accept your false claim as accurate have reason to dismiss any aspect of SWI for literacy instruction at any age.

Clearly, researchers should be seeking new ways of teaching about morphological and phonological aspects of print. The hypothesis that explicit instruction about how morphological structure makes sense of grapheme-phoneme correspondences seems to me like a top candidate for study. We can expect it to bring at least the same benefits we have seen from mostly "isolated morphological instruction." But we also have have reason to predict additional benefits from explicit instruction about how grapheme-phoneme correspondences operate in our writing system.

My hope is that this open letter provides the research community ideas to explore that have too often been underrepresented and misrepresented in the literature.

Peter Bowers, Jan. 31, 2021 Contact author $<$ peterbowers1@mac.com>

\section{References}

Adams, M. J. (1994). Beginning to read: Thinking and learning about print. Cambridge, MA: MIT Press. 
Al Otaiba, S., \& Fuchs, D. (2006). Who are the young children for whom best practices in reading are ineffective? An experimental and longitudinal study. Journal of Learning Disabilities, 39, 414-431.

Anderson, Whiting, Bowers, Venable, (2019), Learning to be literate: An orthographic journey with young students in R. Cox, S. Feez, L. Beveridge (Eds.), The Alphabetic Principle and beyond... surveying the landscape. Primary English Teaching Association Australia (PETAA).

Baumann, J. F., Edwards, E. C., Font, G., Tereshinski, C. A., Kame'enui, E. J., \& Olejnik, S. F. (2002). Teaching morphemic and contextual analysis to fifth-grade students. Reading Research Quarterly, 37, 150-176.

Beck, I., McKeown, M. G., \& Kucan, L. (2002). Bringing words to life: Robust vocabulary instruction. New York: Guilford.

Berko, J. (1958). The child's learning of English morphology. Word, 14, 150-177.

Biemiller, A., \& Boote, C. (2006). An effective method for building vocabulary in primary grades. Journal of Educational Psychology. $44-62$.

Blachowicz, C. L. Z., \& Fisher, P. J. L. (2000). Vocabulary instruction. In R. Barr, M. L. Kamil, P. B. Mosenthal, \& P. D. Pearson (Eds.), Handbook of reading research (Vol. 3, pp. 503523). Mahwah, NJ: Lawrence Erlbaum Associates.

Bower, G. H., Clark, M. C., Lesgold, A. M., \& Winzenz, D. (1969). Hierarchical retrieval schemes in recall of categorized word lists. Journal of Verbal Learning and Verbal Behavior, 8, 323-343.

Bowers, J.S. (2020). Reconsidering the evidence that systematic phonics is more effective than alternative methods of reading instruction. Educational Psychology Review. Advance online publication

Bowers, J. S., \& Bowers, P. N. (2021, January 22). The science of reading provides little or no support for the widespread claim that systematic phonics should be part of initial reading instruction: A response to Buckingham. https://doi.org/10.31234/ osf.io/f5qyu

Bowers, J.S., Bowers, P.N. (2018a). Progress in reading instruction requires a better understanding of the English spelling system. Current Directions in Psychological Science 27, 407-412.

Bowers, J.S., Bowers, P.N. (2018b). The importance of correctly characterising the English spelling system when devising and evaluating methods of reading instruction: Comment on Taylor, Davis, and Rastle (2017). Quarterly Journal of Experimental Psychology, 71, 1497-1500.

Bowers, J.S., Bowers, P.N. (2017). Beyond Phonics: The Case for Teaching Children the Logic of the English Spelling System. Educational Psychologist, 2, 124-141.

Bowers, P.N., Cooke, G. (2012, Fall). Morphology and the Common Core: Building students' understanding of the Written Word. Perspectives on Language and Literacy, 31-35 
Bowers, P.N., Kirby, J.R., \& Deacon, S.H. (2010). The Effects of Morphological Instruction on Literacy Skills: A Systematic

Review of the Literature, Review of Educational Research, 80, 144-179.

Bowers, P.N. \& Kirby, J.R. (2010). Effects of Morphological instruction on Vocabulary Acquisition, Reading and Writing: An Interdisciplinary Journal, 23, 515-537.

Buckingham, J. (2020). Systematic phonics instruction belongs in evidence-based reading programs: A response to Bowers. The Educational and Developmental Psychologist, 37(2), 105-113.

Carlisle, J. F. (2010). Effects of instruction in morphological awareness on literacy achievement: An integrative review. Reading Research Quarterly, 45, 464-487.

Carlisle, J. F. (2007). Fostering morphological processing, vocabulary development, and reading comprehension. In R. K. Wagner, A. E. Muse, \& K. R. Tannenbaum (Eds.), Vocabulary acquisition: Implications for reading comprehension (pp. 78-103). New York: Guilford.

Carlisle, J. F. (2000). Awareness of the structure and meaning of morphologically complex words: Impact on reading. Reading and Writing: An Interdisciplinary Journal, 12, 169-190.

Castles A, Rastle K, Nation K. (2018). Ending the Reading Wars: Reading Acquisition From Novice to Expert. Psychological

Science in the Public Interest, 19-51.

Chomsky, C. (1970). Reading, writing, and phonology. Harvard Educational Review, 40, 287-309.
Chomsky, N., \& Halle, M. (1968). The sound pattern of English. New York: Harper \& Row.

Clark, E. (1982). The young word maker: A case study of innovation in the child's lexicon. In E. Wanner \& L. Gleitman (Eds.), Language acquisition: The state of the art (pp. 390-425).

Cooper, G., \& Sweller, J. (1987). The effects of schema acquisition and rule automation on mathematical problemsolving transfer. Journal of Educational Psychology, 79, 347362.

Craik, F., \& Tulving, E. (1975). Depth of processing and retention of words in episodic memory. Journal of Experimental Psychology: General, 104, 268-294.

Galuschka, K., Görgen, R., Kalmar, J., Haberstroh, S., Schmalz, X. \& Schulte-Körne, G., (2020): Effectiveness of spelling interventions for learners with dyslexia: A meta-analysis and systematic review, Educational Psychologist, DOI:

10.1080/00461520.2019.1659794

Georgiou, G., Savage, R., Dunn, K., Bowers, P., Parrila, R. (2021). Examining the effects of Structured Word Inquiry on the reading and spelling skills of persistently poor Grade 3 readers. Journal of Research in Reading, 44, 131-153.

Goodwin, A. P., \& Ahn, S. (2010). A meta-analysis of morphological interventions: Effects on literacy achievement of children with literacy difficulties. Annals of Dyslexia, 60, 183208. 
Goodwin, A. P., \& Ahn, S. (2013). A meta-analysis of morphological interventions in English: Effects on literacy outcomes for school-age children. Scientific Studies of Reading, $17,257-285$.

Henry, M. K. (1989). Children's word structure knowledge: Implications for decoding and spelling instruction. Reading and Writing: An Interdisciplinary Journal, 2, 135-152.

Henry, M. K. (1988). Beyond phonics: Integrated decoding and spelling instruction based on word origin and structure. Annals of Dyslexia, 38, 259-275.

Henry, M. K. (2003/2010). Unlocking literacy: Effective decoding \& spelling instruction. Baltimore, Maryland: Brookes Publishing.

Kirby, J.R. \& Bowers, P.N. (2012). Morphology Works. What Works? Research into Practice, Ontario Ministry of Education Literacy and Numeracy Secretariat.

Kirby, J. R. \& Bowers, P. N. (2018). The effects of morphological instruction on vocabulary learning, reading, and spelling. In R. Berthiaume, D. Daigle, \& A. Desrochers (Eds.), Issues in Morphological Processing. New York: Routledge.

Kirby, J. R. \& Bowers, P. N. (2017). Morphological instruction and literacy: Binding phonological, orthographic, and semantic features of words. In K. Cain, D. Compton, \& R. Parrila, (Eds.), Theories of reading development. Amsterdam, NL: John Benjamins Publishing Company.
Konkle, T., Brady, T. F., Alvarez, G. A., \& Oliva, A. (2010). Conceptual distinctiveness supports detailed visual long-term memory for real-world objects. Journal of Experimental Psychology: General, 139, 558.

Murphy, A. \& Diehm, E. (2020). Language, Speech, and Hearing Services in Schools, 51, 544-560.

Nagy, W. E. (2005). Why vocabulary instruction needs to be long term and comprehensive. In E. H. Hiebert \& M. L. Kamil (Eds.), Teaching and learning vocabulary: Bringing research to practice (pp. 27-44). Mahwah, NJ: Lawrence Erlbaum Associates.

Nagy, W. E., \& Scott, J. A. (2004). Developing word consciousness. In J. F. Baumann, \& E. J. Kame'enui (Eds.), Vocabulary instruction: Research to practice (pp. 201-217). NY: Guilford.

National Reading Panel (2000). Teaching children to read: An evidence-based assessment of the scientific research literature on reading and its implications for reading instruction. Bethesda, MD: National Institute of Child Health and Human Development.

Ng, M. M. R., Bowers, P. N., \& Bowers, J. S. (2020, March 24). A promising new tool for literacy instruction: The morphological matrix. https://doi.org/10.31234/osf.io/sgejh

Mousikou P, Beyersmann E, Ktori M, Javourey-Drevet L, Crepaldi D, Ziegler JC, Grainger J, Schroeder S. (2020). Orthographic consistency influences morphological processing in reading aloud: Evidence from a cross-linguistic study. Developmental Science, 1-19. 
Perfetti, C. A. (2007). Reading ability: Lexical quality to comprehension. Scientific Studies of Reading, 1, 357-383.

Pinker, S. (1999). Words and Rules. New York, NY: Perennial.

Pressley, M., Disney, L., \& Anderson, K. (2007). Landmark vocabulary instructional research and the vocabulary instructional research that makes sense now. In R. K. Wagner, A. E. Muse, \& K. R. Tannenbaum, (Eds.), Vocabulary acquisition: Implications for reading comprehension. (pp. 205-232). NY: Guilford Press.

Rayner, K., Foorman, B. R., Perfetti, C. A., Pesetsky, D., \& Seidenberg, M. S. (2001). How psychological science informs the teaching of reading. Psychological Science in the Public Interest, 2, 31-74.

Rastle, K., \& Taylor, J. S. H. (2018). Print-sound regularities are more important than print-meaning regularities in the initial stages of learning to read: Response to Bowers \& Bowers (2018). Quarterly Journal of Experimental Psychology, 7, 15011505.

Rastle, (2019a). K. EPS mid-career prize lecture 2017: Writing systems, reading, and language. Quarterly Journal of Experimental Psychology, 4, 677-692.

Rastle, K., (2019b). The place of morphology in learning to read in English, Cortex, 116, 45-54.

Reed, D. K. (2008). A synthesis of morphology interventions and effects on reading outcomes for students in Grades K-12.

Learning Disabilities Research \& Practice, 23, 36-49.
Schnotz, W. \& Kürschner, C. (2007). A reconsideration of cognitive load theory. Educational Psychology Review. 19, 496-508.

Scott, J. A. (2005). Creating opportunities to acquire new word meanings from text. In A. Hiebert \& M. Kamil (Eds.), Teaching and learning vocabulary: Bringing research to practice (pp. 6994). Mahwah, NJ: Lawrence Erlbaum Associates.

Templeton, S. (1989). Tacit and explicit knowledge of derivational morphology: Foundations for a unified approach to spelling and vocabulary development in the intermediate grades and beyond. Reading Psychology, 10, 233-253.

Venezky, R. (1967). English orthography: Its graphical structure and its relation to sound. Reading Research Quarterly, 2, 75105.

Venezky, R. (1970). The structure of English orthography. The Hague, Netherlands: Mouton.

Venezky, R. (1999). The American way of spelling. New York: Guilford.

Verhoeven, L., \& Perfetti, C. A., (2011). Morphological processing in reading acquisition: A cross-linguistic perspective. Applied Psycholinguistics, 32, 457-466. 